\title{
Review \\ Bench-to-bedside review: The promise of rapid infection diagnosis during sepsis using polymerase chain reaction-based pathogen detection
}

\author{
Paul M Dark ${ }^{1-3}$, Paul Dean ${ }^{4}$ and Geoffrey Warhurst ${ }^{2,3,5}$ \\ ${ }^{1}$ Intensive Care Unit, Salford Royal NHS Foundation Trust, Stott Lane, Salford, Greater Manchester, M6 8HD, UK \\ 2Infection, Injury and Inflammation Research Group, Salford Royal NHS Foundation Trust, Stott Lane, Salford, Greater Manchester, M6 8HD, UK \\ ${ }^{3}$ School of Translational Medicine, University of Manchester, Stott Lane, Salford, Greater Manchester, M6 8HD, UK \\ ${ }^{4}$ Department of Anaesthesia and Critical Care, East Lancashire Hospitals NHS Trust, Royal Blackburn Hospital, Haslingden Road, Blackburn, BB2 \\ 3HH, UK \\ ${ }^{5}$ Biomedical Sciences Research Institute, University of Salford, The Crescent, Salford, Greater Manchester, M5 4WT, UK
}

Corresponding author: Paul M Dark, paul.m.dark@manchester.ac.uk

Published: 15 July 2009

This article is online at http://ccforum.com/content/13/4/217

(c) 2009 BioMed Central Ltd
Critical Care 2009, 13:217 (doi:10.1186/cc7886)

management of sepsis as part of the evidence-based guidelines aimed at saving lives [1]. At the core of these guidelines are the early diagnosis of infection as a cause for the patient's systemic inflammatory response and the timely administration of appropriate antimicrobial chemotherapy.

The consensus definitions of infection in critical care require microbiological evidence of pathogens to make a probable diagnosis (for example, Gram stain) or culture to confirm the diagnosis [2]. The Surviving Sepsis Campaign guidelines advocate obtaining at least whole blood and, where possible, other supporting clinical samples for culture prior to the administration of antibiotics, all achieved within 1 hour in a patient with presumed severe sepsis [1]. Current opinion in critical care favours the early use of antibiotics, guided by local pathogen surveillance, usually of a broad spectrum and high potency, that is equally applicable to all clinical settings in patients with suspected severe sepsis [1]. There is evidence showing that the correct initial choice of antibiotic saves more lives than virtually any other intensive care unit intervention [1,3-5]. This may require broad-spectrum cover in the face of as-yet-unidentified infection because delaying antibiotic therapy in sepsis has been shown to increase mortality and morbidity $[6,7]$. Unfortunately, the widespread use of broad-spectrum antibiotics is implicated in the emergence of drug-resistant organisms and rising rates of infection with Clostridium difficile and fungi. Therefore, early de-escalation of antimicrobial agents is a key aim of Surviving Sepsis Campaign guidelines in order to reduce this problem [1].

\section{Importance of rapid infection diagnosis in surviving sepsis}

Sepsis is the clinical syndrome resulting from a host's systemic inflammatory response to infection and is a major international health care problem. The Surviving Sepsis Campaign promotes an important concept of early, goal-directed 


\section{Use and limitations of blood culture in sepsis diagnosis}

Blood cultures have a central role in the detection of pathogenaemia in patients with evidence of the systemic inflammatory response syndrome (SIRS), thus helping differentiate SIRS and sepsis [1]. Positive results enable antibiotic therapy to be rationalised once pathogen identification and antibiotic sensitivities are known. Blood cultures are considered to provide the clinical gold standard in the diagnosis of bloodstream infections [2], and an established evidence base for their appropriate use when assessing and treating suspected sepsis now exists [1]. In addition, blood cultures can have significant diagnostic value in settings for which the establishment of a microbiological diagnosis is otherwise difficult, particularly in deep-seated infections that would otherwise require invasive procedures for samples to be obtained for culture [2]. Surveillance data from blood cultures also constitute an important epidemiological tool on which to base empirical antimicrobial therapy [1].

While a number of clinical and technical factors may affect the isolation of the infecting organism [8], the volume of blood sampled is the most critical factor in the detection of bloodstream infection. The number of organisms present in adult bacteraemia is frequently low, often less than 10 colony-forming units per millilitre $(\mathrm{CFU} / \mathrm{mL})[9,10]$. There is a direct relationship between blood volume and yield, with an approximately $3 \%$ increase in yield per millilitre of blood cultured [10]. National standard laboratories in Europe recommended that at least 20 to $30 \mathrm{~mL}$ of systemic blood be cultured from adults [11], which is reinforced by the Surviving Sepsis Campaign guidelines that promote at least two sets of cultures, which may also include additional blood sampling from established indwelling catheters to help delineate catheter-related infection [1].

Contamination of blood cultures giving a 'false-positive' result remains a significant problem that can limit diagnostic utility in the critically ill and is closely associated with poor patientsampling techniques. Documented rates of contamination vary considerably between institutions, from $0.6 \%$ to over $6 \%$, and the interpretation of these rates continues to be problematic [12]. Clearly, repeating blood culture sets increases sample volume and pathogen yield in the setting of bloodstream infection but is primarily recommended to assist in the recognition of contamination [12].

Despite laboratory techniques aimed at neutralising antimicrobial substances present in a blood sample, the sensitivity of blood cultures decreases greatly when taken after the initiation of antimicrobial therapy $[13,14]$. The use of prophylactic antibiotics and antifungal agents in immunocompromised neutropenic patients, who have a high risk of developing pathogenaemia and who may subsequently show signs of SIRS, makes diagnosis challenging as blood cultures remain negative in many cases [15]. Such patients are also at considerable risk of acquiring infection caused by slowgrowing and fastidious organisms, including fungi, for which blood cultures are poorly sensitive.

The detection and identification of microorganisms based on traditional culture-based methods make time-critical decisionmaking rather difficult because of the significant time lags between patient sampling and results. This can take 2 to 3 days for bacteria and much longer for other fastidious organisms, and as a consequence, the time required to prove absence of infection by culture methods can exceed that of a treatment course of antibiotics [16]. Therefore, although blood cultures remain at the heart of the sepsis care guidelines, emerging alternative technologies aimed at complementing the deficiencies of culture, particularly related to improving time-critical diagnostics, are being investigated.

\section{Polymerase chain reaction approaches to the diagnosis of pathogenaemia}

Molecular methods based on polymerase chain reaction (PCR) technology have been developed for infection diagnosis and pathogen identification. These methods offer a new approach based on detection and recognition of pathogen DNA in the blood, or indeed other clinical samples, with the potential to obtain results in a much shorter time frame (hours) than is possible with conventional culture. PCRbased pathogen detection depends on the ability of the reaction to selectively amplify specific regions of DNA, allowing even minute amounts of pathogen DNA in clinical samples to be detected and analysed. The DNA sequence that is amplified is determined by the design of oligonucleotide primers, short pieces of synthesised DNA that bind to either end of the sequence and form the starting point for DNA replication by DNA polymerase.

For bacterial pathogens, two basic approaches have been taken in assay design, using either specific primers that detect a particular organism or, more commonly, universal primers that bind to conserved sequences in bacterial but not human DNA. The latter approach has the potential to detect a large number of bacterial species in a given sample. Assays that are limited to the detection of a specific organism have often been developed to address a specific clinical need (for example, rapid confirmation of the presence of meningococcoci in patients with meningitis) [17]. In most cases, however, the detection of bloodstream infection requires assays capable of detecting a broad range of pathogens given that several microbial species may be involved, including infections with multiple organisms. To achieve this, the majority of studies have used primers targeting the $16 \mathrm{~S}$ rRNA gene, with a smaller number focusing on the $23 S$ rRNA gene, which also contains conserved sequences. Following PCR of these regions, the pathogen species present can be identified subsequently by sequencing of the amplified DNA followed by phylogenetic analysis using widely available nucleotide databases [18]. Since the 16S rRNA gene 
sequence is ubiquitous in bacteria, this approach has the potential to detect virtually any bacterial pathogen, although some shortcomings have been identified [19]. As early as 1999, Cursons and colleagues [20] showed that PCR directed against the $16 \mathrm{~S}$ ribosomal region was effective in detecting pathogenaemia in a cohort of critically ill patients, although careful optimisation of pathogen DNA extraction was necessary, particularly for the detection of Gram-positive organisms. It was concluded that PCR was more sensitive than conventional blood culture, with a significant proportion of patients being PCR-positive and blood culture-negative. Jordan and colleagues [21] used a similar approach to detect sepsis in neonates but with the addition of pyrosequencing, a technique that enables a more rapid identification of the bacterial species by sequencing short fragments (approximately 30 bases) of the $16 \mathrm{~S}$ rRNA.

The 23S rDNA region shows more sequence variation between bacterial species than 16S, potentially making the former more suitable for discriminating the different bloodborne pathogens encountered in critical care. The few studies that have targeted the $23 \mathrm{~S}$ region show that it is effective in detecting a range of bloodstream infections $[22,23]$. More recently, the gene sequence between the $16 \mathrm{~S}$ and 23 s regions, the so-called internal transcribed region, has been targeted because it contains more variable regions than either $16 \mathrm{~S}$ or $23 \mathrm{~S}$, allowing even better discrimination of bacterial species $[24,25]$.

Perhaps the single most important advance in molecular diagnosis of infection has been the application of real-time PCR. In this technique, the products formed during PCR are monitored continuously as the reaction progresses, using either fluorescent dyes that bind nonspecifically to doublestranded DNA or fluorescently labeled probes that bind to specific sequences. The whole process of PCR amplification, product detection and analysis is achieved in a single reaction vessel. Furthermore, several sequence-specific probes with different fluorescent reporters can be added to the reaction, allowing simultaneous determination of multiple products. This process is therefore ideally suited to infection diagnosis in which a variety of pathogen species could be involved. Another advantage of real-time PCR is that, unlike conventional PCR, it offers the potential to quantify the amount of pathogen DNA present in a clinical sample. Real-time PCR has now been applied in a number of clinical pilot studies. Jordan and Durso [26] recently described a real-time assay based on 16S rDNA which was capable of detecting a range of common pathogens encountered in neonatal sepsis, and when the assay was applied to 85 blood samples from culture-proven sepsis, they reported a 94\% agreement. Subsequently, a number of small studies have indicated the analytical effectiveness of using real-time PCR to detect infection in an adult intensive care setting [25,27-29], although the clinical utility of such measurements requires further evaluation.
The ability to rapidly detect the presence of antibioticresistant organisms is an increasingly important consideration in intensive care. Conventional antimicrobial susceptibility tests require culture of the organism from the clinical sample with a further delay of at least 24 to 48 hours before results are available. Once the genetic differences that underlie drug resistance in a particular species are known, it is feasible to develop PCR assays able to rapidly identify resistant organisms directly in clinical samples [30]. This approach has been successfully applied to the detection of methicillinresistant Staphylococcus aureus (MRSA) in various clinical samples with assays aimed at the mecA and fem $A$ genetic elements that cause resistance. A study of tracheal aspirates from mechanically ventilated patients showed concordance between PCR and conventional culture in 57 out of 60 MRSA-positive samples [31]. Furthermore, of the three discordant results (PCR-positive, conventional-negative), all three were later shown to be MRSA-positive through complementary bacteriological testing. Similarly, Louie and colleagues [32] showed diagnostic sensitivity and specificity of $99 \%$ and $100 \%$, respectively, for PCR in a study of 306 patients with MRSA bacteraemia with PCR data available within 3 hours. More importantly, it has now been shown that the introduction of PCR screening for MRSA in critical care has a significant impact on transmission rates, with an associated relative risk reduction of 0.65 and a $95 \%$ confidence interval of 0.28 to 1.07 , in a cohort of 1,305 critically ill patients [33]. While PCR may be appropriate in identifying resistance in specific organisms, it is unlikely in general to be the most effective way of screening for drug resistance given the hundreds of known resistance genes. The use of other genetic techniques (such as DNA microarray) which allow simultaneous analysis of a large number of drug-resistance genes in diverse bacteria is under investigation [34].

Fungal infections are also targets for the development of molecular diagnostic techniques. Infections with Aspergillus and Candida species are increasingly important in intensive care and are associated with high morbidity and mortality. However, current diagnostic procedures like mycological culture or microscopy require either long growth periods or suffer from poor sensitivity. Several PCR assays aimed at identifying specific fungal species have been developed, although this approach has limitations given that in a proportion of cases infections may be polymicrobial. A recent review showed that, in the case of Aspergillus, most PCR assays were targeting the two most prevalent types, Aspergillus fumigatus and A. flavus, which represent only 2 out of the $\mathbf{2 0}$ or so Aspergillus species that have been shown to cause opportunistic infections in humans [35]. Studies comparing PCR methods with the enzyme-linked immunosorbent assay (ELISA) test for Aspergillus antigen and other markers used in the diagnosis of invasive pulmonary aspergillosis have reported diagnostic sensitivity of $79 \%$ for PCR compared with $58 \%$ and $67 \%$ for ELISA and other 
markers, respectively; diagnostic specificity was $92 \%$ for PCR compared with $97 \%$ for ELISA and $84 \%$ for the other diagnostic tests, respectively. Importantly, results of PCR were available more quickly than those of the other diagnostic tests [35]. More recently, broad-range real-time PCR assays for fungal species have been developed [36,37]. Schabereiter-Gurtner and colleagues [37] used a combination of universal primers and group-specific probes to identify 11 clinically relevant Aspergillus and Candida species in a range of clinical samples, including blood, tracheal aspirates and cerebrospinal fluid. The assay was able to detect fungal infections with high analytical sensitivity (for example, 5 to $10 \mathrm{CFU} / \mathrm{mL}$ blood).

In terms of clinical utility in sepsis, the most effective PCR approach would be one in which both bacterial and fungal species could be detected and identified in a single assay. Roche Diagnostics (Basel, Switzerland) has introduced the SeptiFast ${ }^{\mathrm{TM}}$ platform following recent European regulatory approval. SeptiFast ${ }^{\mathrm{TM}}$ is a commercial real-time PCR diagnostic kit that is designed to detect and identify 25 bacterial and fungal species that make up greater than $90 \%$ of the pathogens causing bloodstream infections in critical care, with a sensitivity of between 3 and $30 \mathrm{CFU} / \mathrm{mL}$ [25]. To date, there has been only limited published evidence of the clinical utility of SeptiFast ${ }^{\mathrm{TM}}$. A recent study by Louie and colleagues [38] in 200 patients with clinical suspicion of sepsis recruited from a mixture of intensive care and general medicine acute wards showed that SeptiFast ${ }^{\mathrm{TM}}$ detected more instances of pathogenaemia than did blood culture, with results available potentially within 6 hours. However, that study also reported several false-negatives in which culture detected an organism that was not present on the SeptiFast ${ }^{\mathrm{TM}}$ PCR panel, a limitation of the current platform. Broadly similar findings with SeptiFast ${ }^{\mathrm{TM}}$ have been reported in a group of haematology patients with suspected sepsis [39]. A second commercial system for diagnosis of bloodstream infection, SepsiTest ${ }^{\mathrm{TM}}$ (Molzym GmbH \& Co. KG, Bremen, Germany), recently gained European regulatory approval. This test takes a different approach, using universal primers to report the presence of a bacterial or fungal DNA in blood with species identification relying on post-test sequencing of the products. To date, there have been no published studies evaluating the use of SepsiTest ${ }^{\mathrm{TM}}$ in a clinical setting.

\section{Key issues in the application of polymerase chain reaction to the diagnosis and management of sepsis}

The application of PCR techniques to detect and identify pathogens has the potential to revolutionise the diagnosis and management of sepsis. Unlike microbiological culture, a PCR diagnosis confirming the absence or presence of a pathogen, along with species identification, could be available to the clinician in a few hours. However, there remain a number of unresolved questions about the interpretation of PCR clinical data and the significance of circulating pathogen
DNA as a marker of infection. There are several possible reasons for frequently reported so-called 'false' positives in which PCR shows evidence of pathogen DNA in the absence of culturable organisms. Given the sensitivity of the PCR technique, it is important to rule out the possibility that a 'false' positive occurs as a result of environmental contamination, although these events can be minimised by adoption of strict procedures for sample collection and processing [25]. PCR may also give a positive result in the absence of intact pathogens since it does not distinguish between DNA associated with viable bacteria and DNA originally from intact bacteria in the circulation which have been destroyed as a result of host immune responses and/or recent antibiotic administration. Further studies are needed to monitor the kinetics of bacteria DNA appearance and clearance from the blood during infection and antibiotic treatment. It is important to consider that 'false' positives may have biological significance and provide information of diagnostic value. For example, freely circulating pathogen DNA may be a biomarker of infection at extracirculatory sites due to shedding of pathogen DNA into the circulation. With this in mind, the adoption of techniques that separate intact organisms in blood, or other fluids, prior to DNA extraction [40] would allow discrimination between the presence of DNA associated with intact pathogens and free pathogen DNA. Such DNA separation may help investigators to understand the high rates of 'false-positive' PCR results in blood from patients with suspected sepsis and potentially provide valuable information on the broader infection phenotype in an individual. In recognising the potential limitations of PCR for detecting infection, it is also important to balance these against uncertainties in the current 'gold standard' of microbiological culture.

Despite the significant potential benefits in reducing unnecessary antibiotic use in critical care, there has been little discussion so far regarding the value of a negative PCR result from blood ruling out sepsis in patients who are subsequently shown on culture to have no evidence of infection. However, here again, careful validation of pathogen PCR is required since instances of negative PCR results associated with positive blood culture are reported, although these are relatively infrequent and, in many cases, appear to be the result of the organism's not being included in the particular PCR panel [41]. Similar considerations apply to the application of PCR to other clinical samples such as sputum for the diagnosis of nosocomial respiratory infections such as ventilator-associated pneumonia. However, additional samplespecific issues may arise such as the high background levels of commensal organisms likely to be present in the respiratory tract which may make clinical interpretation of PCR data more difficult.

\section{Conclusions}

There is real promise of rapid infection diagnosis in suspected sepsis using PCR pathogen detection as evidenced 
by its inclusion as an emerging technology in recent Surviving Sepsis Campaign publications and by the early commercialisation of these molecular laboratory techniques for application in critical care. While culture techniques offer the best practice today, limitations, particularly in terms of their time constraints and their sensitivities in patients already exposed to antibiotics, are significant. However, the promise of rapid PCR-driven single-blood-sample diagnostics in this arena has yet to be realised, and only a few peer-reviewed observational studies using the emerging commercially available systems have been published. Therefore, we have the opportunity now to drive a thorough health technology assessment process of the available PCR systems from laboratory diagnostic validation through to appropriately powered, well-designed clinical validation and effectiveness studies in populations of critically ill patients who would most likely benefit. We anticipate that, if PCR technologies prove to have acceptable clinical diagnostic validity, subsequent clinical effectiveness studies are most likely to prove cost-efficient when comparing standard culture with PCR in delivering early antibiotic deescalation. Until such processes have been completed and reported, we cannot recommend technology adoption. We also believe that a systematic approach to the investigation of pathogen DNAemia during critical illness will help delineate patient phenotypes in the SIRS/sepsis spectrum and provide a firmer understanding of the biology of pathogen DNA that underpins rapid PCR-based diagnostics. Furthermore, the feasibility of determining antibiotic sensitivities at a gene level for a range of pathogens associated with sepsis remains to be investigated but should not delay the assessment of the currently available commercial platforms aimed at pathogen detection and identification.

\section{Competing interests}

PMD has received rail travel costs from Roche Diagnostics to allow the presentation of PCR-based pilot data of infection diagnosis at a UK national education meeting. The research laboratories of GW and PMD have performed service evaluations of SeptiFast ${ }^{\mathrm{TM}}$, SepsiTest ${ }^{\mathrm{TM}}$ and noncommercial multiplex PCR platforms; SeptiFast ${ }^{\mathrm{TM}}$ was provided free of charge for this purpose by Roche Diagnostics UK. We have not received any funding or sponsorship for this article. This article represents our views, based on our experiences within the National Health Service, of this and other PCR-based assays and not necessarily the views of Roche Diagnostics.

\section{References}

1. Dellinger RP, Levy MM, Carlet JM, Bion J, Parker MM, Jaeschke R, Reinhart K, Angus DC, Brun-Buisson C, Beale R, Calandra T, Dhainaut JF, Gerlach H, Harvey M, Marini JJ, Marshall J, Ranieri M, Ramsay G, Sevransky J, Thompson BT, Townsend S, Vender JS, Zimmerman $J \mathrm{~L}$, Vincent JL; for the International Surviving Sepsis Campaign Committee: International guidelines for management of severe sepsis and septic shock. Crit Care Med 2008, 36:296-327.

2. Calandra T, Cohen J; for the International Sepsis Forum Definition of Infection in the ICU Consensus Conference: The International Sepsis Forum Consensus Conference on Definitions of Infection in the Intensive Care Unit. Crit Care Med 2005, 33:15381548.
3. Kollef MH, Sherman G, Ward S, Fraser VJ: Inadequate antimicrobial treatment of infections: a risk factor for hospital mortality among critically ill patients. Chest 1999, 115:462-474.

4. Garnacho-Montero J, Garcia-Garmendia JL, Barrero-Almodovar A, Jimenez-Jimenez FJ, Perez-Paredes C, Ortiz-Leyba C: Impact of adequate antibiotic therapy on the outcome of patients admitted to intensive care unit with sepsis. Crit Care Med 2003, 31:2742-2751.

5. Valles J, Rello J, Ocagavia A, Garnacho J, Alcala MA: Community acquired bloodstream infection in critically ill adult patients: impact of shock and inappropriate antibiotic therapy on survival. Chest 2003, 123:1615-1624.

6. Fraser A, Paul M, Almanasreh N, Tacconelli E, Frank U, Cauda R, Borok S, Cohen M, Andreassen S, Nielson AD, Leibovici L; TREAT Study Group: Benefit of appropriate empirical antibiotic treatment. Thirty day mortality and duration of hospital stay. Am J Med 2006, 119:970-976.

7. Kumar A, Roberts D, Wood KE, Light B, Parrillo JE, Sharma S, Suppes R, Feinstein D, Zanotti S, Taiberg L, Gurka D, Kumar A, Cheang M: Duration of hypotension before initiation of effective antimicrobial therapy is the critical determinant of survival in human septic shock. Crit Care Med 2006, 34: 1589-1596.

8. Peters RP, Van Agtmael MA, Danner SA, Savelkoul PM, Vandenbroucke-Grauls CM: New developments in diagnosis of bloodstream infections. Lancet Infect Dis 2004, 4:751-760.

9. Arpi M, Bentzon MW, Jensen J, Frederiksen W: Importance of blood volume cultured in the detection of bacteremia. Eur $J$ Clin Microbiol Infect Dis 1989, 8:838-842.

10. Mermel LA, Maki DG: Detection of bacteremia in adults: consequences of culturing an inadequate volume of blood. Ann Intern Med 1993, 119:270-272.

11. Department for Evaluations, Standards and Training (DEST) [http://www.evaluations-standards.org.uk].

12. Hall KK, Lyman JA: Updated review of blood culture contamination. Clin Micro Rev 2006, 19:788-802.

13. McKenzie R, Reimer LG: Effect of antimicrobials on blood cultures in endocarditis. Diag Microbiol Infect Dis 1987, 8:165172.

14. Glerant JC, Hellmuth D, Schmit JL, Ducroix JP, Jounieaux V: Utility of blood cultures in community-acquired pneumonia requiring hospitalization: influence of antibiotic treatment before admission. Respir Med 1999, 93:208-212.

15. Serody JS, Berrey MM, Albritton K, O'Brien SM, Capel EP, Bigelow SH, Weber DJ, Gabriel DA, Wiley JM, Schell MJ, Gilligan $\mathrm{PH}$, Shea TC: Utility of obtaining blood cultures in febrile neutropenic patients undergoing bone marrow transplantation. Bone Marrow Transplant 2000, 26:533-538.

16. Munson EL, Diekema DJ, Beekmann SE, Chapin KC, Doern GV: Detection and treatment of bloodstream infection: laboratory reporting and antimicrobial management. J Clin Microbiol 2003, 41:495-497.

17. Seward RJ, Towner KJ: Evaluation of a PCR-immunoassay technique for detection of Neisseria meningitidis in cerebrospinal fluid and peripheral blood. J Med Microbiol 2000, 49:451-456.

18. Zucol F, Ammann RA, Berger C, Aebi C, Altwegg M, Niggli FK, Nadal D: Real-time quantitative broad-range PCR assay for detection of the 16S rRNA gene followed by sequencing for species identification. J Clin Microbio/ 2006, 44:2750-2759.

19. Janda JM, Abbott SL: 16S rRNA gene sequencing for bacterial identification in the diagnostic laboratory: pluses, perils, and pitfalls. J Clin Microbiol 2007 45:2761-2764.

20. Cursons RT, Jeyerajah E, Sleigh JW: The use of polymerase chain reaction to detect septicemia in critically ill patients. Crit Care Med 1999, 27:937-940.

21. Jordan JA, Butchko AR, Durso MB: Use of pyrosequencing of $16 \mathrm{~S}$ rRNA fragments to differentiate between bacteria responsible for neonatal sepsis. J Mol Diagn 2005, 7:105-110.

22. Anthony RM, Brown TJ, French GL: Rapid diagnosis of bacteremia by universal amplification of 235 ribosomal DNA followed by hybridization to an oligonucleotide array. J Clin Microbiol 2000, 38:781-788.

23. Rantakokko-Jalava K, Nikkari S, Jalava J, Eerola E, Skurnik M, Meurman O, Ruuskanen O, Alanen A, Kotilainen E, Toivanen P, Kotilainen P: Direct amplification of rRNA genes in diagnosis of bacterial infections. J Clin Microbiol 2000, 38:32-39. 
24. Gürtler V, Stanisich VA: New approaches to typing and identification of bacteria using the 16S-23S rDNA spacer region. Microbiology 1996, 142:3-16.

25. Lehmann LE, Hunfeld KP, Emrich T, Haberhausen G, Wissing $H$, Hoeft A, Stüber F: A multiplex real-time PCR assay for rapid detection and differentiation of 25 bacterial and fungal pathogens from whole blood samples. Med Microbiol Immunol 2008, 197:313-324.

26. Jordan JA, Durso MB: Real-time polymerase chain reaction for detecting bacterial DNA directly from blood of neonates being evaluated for sepsis. J Mol Diagn 2005, 7:575-581.

27. Peters RP, van Agtmael MA, Gierveld S, Danner SA, Groeneveld $A B$, Vandenbroucke-Grauls CM, Savelkoul PH: Quantitative detection of Staphylococcus aureus and Enterococcus faecalis DNA in blood to diagnose bacteremia in patients in the intensive care unit. J Clin Microbio/ 2007, 45:3641-3646.

28. Ohlin $A$, Bäckman $A$, Björkqvist $M$, Mölling $P$, Jurstrand $M$, Schollin J: Real-time PCR of the 16S-rRNA gene in the diagnosis of neonatal bacteraemia. Acta Paediatr 2008, 97:13761380.

29. Schabereiter-Gurtner C, Nehr M, Apfalter P, Makristathis A, Rotter ML, Hirschl AM: Evaluation of a protocol for molecular broad-range diagnosis of culture-negative bacterial infections in clinical routine diagnosis. J Appl Microbiol 2008, 104:12281237.

30. Sundsfjord A, Simonsen GS, Haldorsen BC, Haaheim H, Hjelmevoll SO, Littauer P, Dahl KH: Genetic methods for detection of antimicrobial resistance. APMIS 2004, 112:815-837.

31. Vannuffel P, Laterre PF, Bouyer M, Gigi J, Vandercam B, Reynaert $M$, Gala JL: Rapid and specific molecular identification of methicillin-resistant Staphylococcus aureus in endotracheal aspirates from mechanically ventilated patients. J Clin Microbiol 1998, 36:2366-2368.

32. Louie L, Goodfellow J, Mathieu P, Glatt A, Louie M, Simorn AE: Rapid detection of methicillin-resistant Staphylococci from blood culture bottles by using a multiplex PCR Assay. J Clin Microbio/ 2002, 40:2786-2790.

33. Cunningham R, Jenks $P$, Northwood J, Wallis M, Ferguson $S$, Hunt S: Effect on MRSA transmission of rapid PCR testing of patients admitted to critical care. J Hosp Infect 2007, 65:2428.

34. Frye JG, Jesse T, Long F, Rondeau G, Porwollik S, McClelland M, Jackson CR, Englen M, Fedorka-Cray PJ: DNA microarray detection of antimicrobial resistance genes in diverse bacteria. Int $J$ Antimicrob Agents 2006 27:138-151.

35. Espy MJ, Uhl RJ, Sloan LM, Buckwalter SP, Jones MF, Vetter EA, Yao JD, Wengenack NL, Rosenblatt JE, Cockerill FR 3rd, Smith TF: Real-time PCR in clinical microbiology: applications for routine laboratory testing. Clin Microbiol Rev 2006, 19:165256.

36. Vollmer T, Störmer M, Kleesiek K, Dreier J: Evaluation of novel broad-range real-time PCR assay for rapid detection of human pathogenic fungi in various clinical specimens. J Clin Microbiol 2008, 46:1919-1926.

37. Schabereiter-Gurtner C, Selitsch B, Rotter ML, Hirschl AM, Willinger B: Development of novel real-time PCR assays for detection and differentiation of eleven medically important Aspergillus and Candida species in clinical specimens. J Clin Microbio/ 2007, 45:906-914

38. Louie RF, Tang Z, Albertson TE, Cohen S, Tran NK, Kost GJ: Multiplex polymerase chain reaction detection enhancement of bacteremia and fungemia. Crit Care Med 2008, 36:1487-1492.

39. Mancini N, Clerici D, Diotti R, Perotti M, Ghidoli N, De Marco D, Pizzorno B, Emrich T, Burioni R, Ciceri F, Clementi M: Molecular diagnosis of sepsis in neutropenic patients with haematological malignancies. J Med Microbio/ 2008, 57:601-604.

40. Handschur M, Karlic H, Hertel C, Pfeilstöcker M, Haslberger AG: Preanalytic removal of human DNA eliminates false signals in general 16S rDNA PCR monitoring of bacterial pathogens in blood. Comp Immunol, Microbiol Infect Dis 2009, 32:207-219.

41. Falagas ME, Panayotis TT: Enhanced and earlier detection of bacteremia and fungemia by multiplex polymerase chain reaction: How much enhanced, how much earlier and at what cost? Crit Care Med 2008, 36:1660-1661. 